\title{
A STUDY ON CHILD SEXUAL ABUSE IN SCHOOL GOING CHILDREN
}

\author{
Harisha Delanthabettuํ, Kasturi Pandiyan², Sandhya Kaveri $K^{3}$, Ramachandra V. Gunari4, Shubha N. Vijayakumar 5 \\ 1Professor, Department of Psychiatry, K.V.G Medical College, Sullia, DK, Karnataka. \\ ${ }^{2}$ Assistant Professor, Department of Psychiatry, BMC and RI, Bangalore, Karnataka. \\ ${ }^{3}$ Principal, Kateel Ashok Pai Memorial Institute, Shivamogga. \\ ${ }^{4}$ Counselor, Ankura Counseling Centre, Shivamogga. \\ ${ }^{5}$ Counselor, Vimalasri Consultation, Bhadravathi.
}

ABSTRACT

\section{BACKGROUND}

Child sexual abuse (CSA) is a major public health concern worldwide. India is home to the largest child population with almost 42 percent of our country's population under eighteen years of age. In 2007, the Government of India published its first report on CSA. This report reveals over 53\% of the children interviewed having faced some form of CSA. Over 57\% of these were boys and $72 \%$ said they did not report the abuse to anyone. Only 3\% reported CSA to the Police. CSA can take place in a variety of settings- at home, school, in the community and workplace. The study on child abuse conducted by the Ministry of Women and Child Development of the Government of India in 2007 found that in most cases the perpetrator was known to the child. Perpetrators build trust with the child to prevent disclosure and at times threaten them to maintain silence.

The aim of this study is to assess the prevalence and burden of child sexual abuse in school going children of Shimoga District, India; and the objective is to estimate the prevalence, awareness and types of child sexual abuse in school going children.

\section{MATERIALS AND METHODS}

A semi-structured questionnaire was prepared in Kannada and English. A brief introduction to child sexual abuse was given to the children from $8^{\text {th }}$ to $12^{\text {th }}$ standard from April to July 2015. The students were reassured about anonymity and "no repercussions" to get unbiased information. The Questionnaire was given to the students to fill, which was then collected and tabulated. The analysis was done using SPSS and the result was obtained.

\section{RESULTS}

Total of 1336 students filled the questionnaire, out of them 165 (12.35\%) reported to have experienced at least one form of sexual abuse. The statistics showed 97 (7.2\%) of them were boys and 68 (5.08\%) were girls; showing nude photos or sexual videos when they did not want it was the most common form of sexual abuse $59(35.5 \%)$ followed by being touched in their private parts 54 (32.1\%) and forced to touch other's private parts 44 (26.7\%) and others. Known and unknown adults (Unrelated) 54 (38.8\%) are the most common abusers followed by friends 32 (23\%). Among them, 78 (51.7\%) of them kept quiet or ignored and $26(17.2 \%)$ of them informed parents or guardians.

\section{CONCLUSION}

Prevalence of Child Sexual Abuse is $12.5 \%$ across Shimoga District. Boys have reported as per the standard, but girls reporting are less (? Good/Hidden).

\section{KEYWORDS}

Child Sexual Abuse, Prevalence, Awareness, School Going Children.

HOW TO CITE THIS ARTICLE: Delanthabettu H, Pandiyan K, Kaveri SK, et al. A study on child sexual abuse in school going children. J. Evolution Med. Dent. Sci. 2017;6(67):4798-4801, DOI: 10.14260/Jemds/2017/1040

\section{BACKGROUND}

Child sexual abuse is a major public health concern worldwide. India is home to the largest child population with almost 42 percent of our country's population under eighteen years of age. In 2007, the Government of India published its first report on CSA. This report reveals over $53 \%$ of the children interviewed having faced some form of CSA. Over $57 \%$ of these were boys and $72 \%$ said they did not

Financial or Other, Competing Interest: None.

Submission 08-07-2017, Peer Review 09-08-2017,

Acceptance 16-08-2017, Published 21-08-2017.

Corresponding Author:

Dr. Harisha Delanthabettu,

Professor of Psychiatry,

K.V.G Medical College \& Hospital,

Sullia, D.K, Karnataka.

E-mail: drharishad@gmail.com

DOI: $10.14260 /$ jemds $/ 2017 / 1040$ police. According to the National Family Health Survey (NFHS 3, 2005 - 6), 4.5 percent of girls aged 15 - 19 years (married or unmarried) have experienced forced intercourse or another form of a forced sexual act.(1) The majority of the girls who experienced forced sexual intercourse suffered sexual violence between the age of 15 and 19 years, although some girls experienced throughout the childhood. The experience of sexual violence in childhood can have adverse consequences for the child's physical, mental and social development. Apart from the injuries that may result from the violence, there is also risk of sexually transmitted diseases as well as of early pregnancy. In addition to this, there is a risk of self-harming behaviours including attempts to commit suicide.

CSA can take place in a variety of settings: at home, school, in the community or workplace. The 'study on child abuse' conducted by the Ministry of Women and Child Development of the Government of India in 2007 found that 
in most cases the Perpetrator was known to the child.(2) As per the same study, $31 \%$ of sexual assaults were committed by the victim's uncle or neighbour. Perpetrators build trust with the child to prevent disclosure and at times threaten them to maintain silence.

Under the Protection of Children from Sexual Offences (POCSO) Act 2012, any sexual activity with a child below 18 years whether boy or girl is a crime. As defined by the Act, sexual offences include penetrative sexual assault (Section 3), sexual assault (i.e. non-penetrative) (Section 7), sexual harassment (Section 11) and use of a child for pornography (Section 13).(3)

According to the Adverse Childhood Experiences (ACE) Study, a major American research project examining the effects of adverse childhood experiences on adult health and well-being, a powerful relationship has been established between emotional experiences during childhood and physical and mental health during adulthood. Sexual abuse is an extremely traumatic experience that can affect the body as well as the mind, and the reaction of the body and the mind to such an occurrence could leave a lasting impact on the health conditions for any person at any age. Studies have consistently demonstrated that sexual abuse suffered in childhood is associated with a broad range of behavioural, psychological and physical problems that persist into adulthood. These include anxiety, depression, Post-Traumatic Stress Disorder (PTSD), self-destructive behaviour, dissociation, substance abuse, sexual maladjustment and a tendency towards re-victimisation in subsequent relationships.(4)(5) Adult survivors of childhood physical, emotional or sexual abuse are not only at increased risk for depression and other mental health disorders, but new evidence suggests they are increasingly more likely to suffer from heart disease, obesity and other potentially fatal physical conditions.

The major barrier in the prevention of child abuse is to acknowledge that it exists in society. It took several decades of effort in the countries that now have a substantial reduction in child abuse, in acknowledging the fact that child abuse and neglect can be prevented. Therefore, understanding the extent of the problem is the first step towards efforts at prevention. ${ }^{(6)}$

It is imperative that the right kind of intervention and opportunity for recovery be provided at the right time. Doctors, nurses and other health sector professionals are important stakeholders in the prevention and response to sexual violence against children. This is why the role of the health sector is such an important one.(7)

\section{Aim}

To assess the prevalence and burden of child sexual abuse in school going children.

\section{Objective}

To estimate the prevalence, awareness and types of child sexual abuse in school going children.

\section{MATERIALS AND METHODS}

\section{Study Design and Population}

This is an epidemiological, retrospective and cross-sectional study conducted among the school going children in Shimoga district, Karnataka, India. This is an observational study. The schools and colleges were chosen conveniently, so that all regions of Shimoga district were represented. The sample size was 1336 and was calculated as for convenience.

\section{Inclusion Criteria}

Age Group: 12 - 18 years. Both girls and boys who are willing to answer the questionnaire are included in the study. A semi-structured questionnaire was prepared in Kannada and English. A brief introduction to child sexual abuse was given to the children from $8^{\text {th }}$ to $12^{\text {th }}$ standard of Shimoga District, Karnataka. The children were explained about need for the survey on child sexual abuse and bring about awareness on the topic. Children who find it difficult to understand the questionnaire are provided help to fill the questionnaire. Consent was taken by explaining and attaching the consent form along with the survey. Assent was taken from school and parents. The study was started in April 2015 and was completed by July 2015 with total of 1336 participants who answered the questionnaire. Followed by assuring the child of confidentiality, the questionnaire was given to the students to fill, which was then collected and tabulated. The analysis was done using IBM SPSS statistics 21 and the result obtained. Ethics committee approval was taken.

\section{Exclusion Criteria}

Children who are unwilling to participate were not included in the study.

\section{RESULT}

Total of 1336 students filled the questionnaire. Out of 1336 males were 551, females were 770 and 15 questionnaires were missing the gender field, left unanswered. On analysing the data, it was found that 165 (12.35\%) children answered YES for having experienced at least one form of sexual abuse, while the other 1171 (87.65\%) answered NO. The statistics showed among those children who answered YES 97 (7.2\%) of them were boys and $68(5.08 \%)$ were girls. Child sexual abuse Fig. 1 in decreasing order of numbers and percentage of the total abused in our study is as follows.

Showing nude photos or sexual videos to children when they did not want it was the most common form of sexual abuse 59 (35.5\%) among the children of Shimoga. Followed by being touched in their private parts in 54 (32.1\%) children and forced to touch other's private parts in 44 (26.7\%) children; 36 (21.8\%) children were forced to show their private parts and $35(21.2 \%)$ children were showed other's private parts to see against their will or in ignorance; 34 (20.6\%) children were kissed by force and in 24 (14.54\%) children the abuser tried to take nude photo of them; 16 $(9.69 \%)$ children were abused with sexual intercourse by the abuser. 


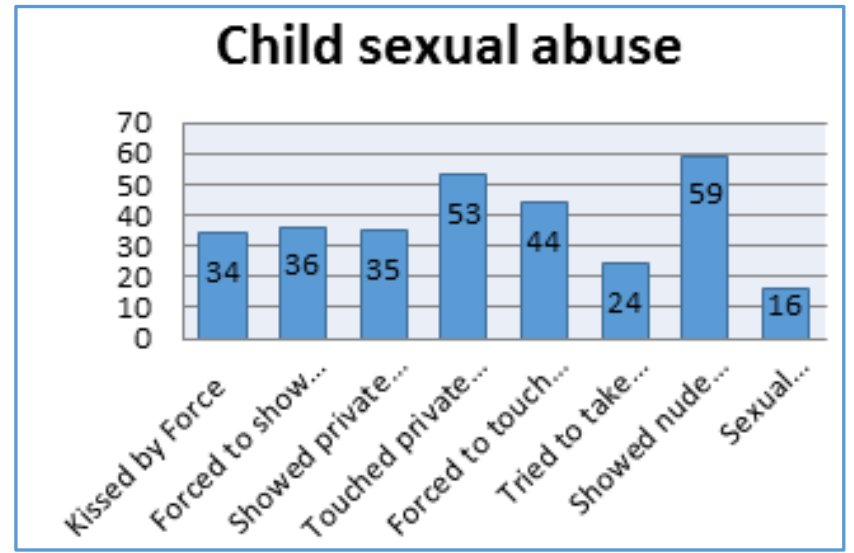

Figure 1. Child Sexual Abuse

\section{Abuser}

Among the abusers or perpetrator known and unknown adults (both unrelated) 54 are the most common abusers followed by friends 32 , siblings 19 , relatives 18 , parents 15 and guardians 1 . Out of 165 children that were abused 120 of them stayed with parents and 14 stayed with guardians, rest with other relatives (Fig. 2).

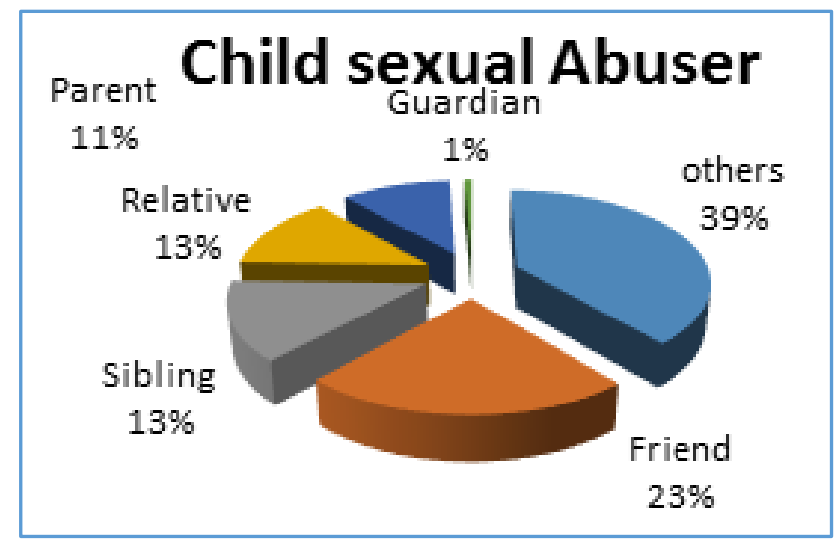

Figure 2. Pie Chart showing the CSA Perpetrator

\section{Disclosure}

Among the 165 children that were abused, 78 children kept quiet or ignored the abuse according to the data obtained. It constitutes more than $50 \%$ of the abused children. Only 19 children and their caretakers have reported the incident to the police. Others even though disclosed to parents, siblings, friends or guardians were not reported to the police (Table 1).

\begin{tabular}{|c|c|c|c|c|}
\hline Sl. No. & Disclosed & To Whom & No. & \% \\
\hline 1 & No & $\begin{array}{c}\text { Kept quiet or } \\
\text { Ignored }\end{array}$ & 78 & $51.7 \%$ \\
\hline 2 & Yes & $\begin{array}{c}\text { Informed } \\
\text { parents/guardians }\end{array}$ & 26 & $17.2 \%$ \\
\hline 3 & Yes & $\begin{array}{c}\text { Informed } \\
\text { Brothers/sisters }\end{array}$ & 5 & $3.3 \%$ \\
\hline 4 & Yes & Informed Friends & 19 & $12.6 \%$ \\
\hline 5 & Yes & Reported to Police & 19 & $12.6 \%$ \\
\hline 6 & Yes & Others (Unrelated) & 4 & $2.6 \%$ \\
\hline \multicolumn{5}{|c|}{ Table 1. Disclosure of Child Sexual Abuse } \\
\hline
\end{tabular}

\section{DISCUSSION}

Since CSA affects approximately 1 in 4 girls and 1 in 7 boys, in our survey we found that $12.5 \%$ of the participants revealed that they have suffered at least one form of CSA. According to Stoltenborgh et al 2011, the CSA prevalence rate in Asia among females is $11.3 \%$ and males is $4.1 \%$, but in our study showed that girls were $5.08 \%$ and males were $7.2 \%$.(8) This could be because many girl children participated were unwilling to disclose due to various reasons. A survey conducted by NGOs in 2005 in Chennai among school going children, $48 \%$ of the boys and $39 \%$ of the girls had faced some form of CSA in their lifetime which is very high compared to our survey with $7.2 \%$ boys and $5.08 \%$ for girls. (9) This may be due the differences in survey and the methodology and the target population. But the higher percentage of disclosure among boys is in line with our survey.

According to the data published by the Indian government report on CSA in 2007, over $53 \%$ of the study population reported having faced some form of CSA. In Shimoga district, India, it was $12.5 \%$ of the study population; $58 \%$ of those who faced CSA according to our survey were boys, which is in agreement with the CSA report of 2007, India - over $57 \%$ were boys. The report also showed that $72 \%$ of the abused children never reported to anyone but in our survey $51.7 \%$ never reported to anyone; $17.2 \%$ reported to parents/ guardians and amp; $12.6 \%$ reported to friends and $12.6 \%$ reported to police, but in the CSA report 2007 India reporting to police was only $3 \%$. These variations may be due to differences in size of the study target population, geography, questionnaire structure and the willingness of the participant to disclose. About $1 / 3$ of perpetrators are juveniles and $40 \%$ of child victims are under 6 years old. In our study, majority were adult and were known to the victims.

The emphasis of all these surveys throws light on awareness among Indian population, especially the parents, teachers and children about CSA and how to identify and report it.

\section{Limitation}

It is a retrospective study with recall bias and understanding.

\section{Implication}

Awareness and safety of children is a must. Reporting of child sexual abuse is mandatory for medical professionals under the POCSO Act. It is not compulsory to inform the child and family of the reporting, but it is a good practice. A multidisciplinary approach is required in the management of CSA cases.

\section{CONCLUSION}

Prevalence of Child Sexual Abuse is $12.5 \%$ across Shimoga District. Boys have reported as per the standard, but girls reporting are less (? Good/Hidden).

\section{REFERENCES}

[1] Unicef. Hidden in plain sight: a statistical analysis of violence against children 2014. Available at: http://data.unicef.org/resources/hidden-in- plainsight\#sthash.rulg9e8E.dpuf. 
[2] Ministry of women and child development, government of India, study on sexual abuse: India 2007.

[3] Ministry of women and child development, government of India: model guidelines under section 39 of the protection of children from sexual offences act 2012. Available at:

http://wcd.nic.in/act/POCSO\%20-\%20 Model\% 20 Guidelines.

[4] Browne A, Finkelhor D. Impact of child sexual abuse: a review of the research. Psychological Bulletin 1986;99(1):66-77.

[5] Finkelhor D. Early and long-term effects of child sexual abuse: an update. Professional Psychology 1990;21(5):325-30.
[6] World Health Organization. Regional office for SouthEast Asia. Managing child abuse: a handbook for medical officers 2004.

[7] Child sexual abuse: prevention and relapse, information for health care professional 2015.

[8] Stoltenborgh M, van Ijzendoorn MH, Euser EM, et al. A global perspective on child sexual abuse: metaanalysis of prevalence around the world. Child Maltreat 2011;16(2):79-101.

[9] Singh MM, Parsekar SS, Nair SN. An epidemiological overview of child sexual abuse. J Family Med Prim Care 2014;3(4):430-5. 